\title{
Acute Effect of Aerobic Exercise on Cardiovascular Reactivity of Overweight Males
}

\author{
David Chandrakumar ${ }^{1}$, Daria Dyck ${ }^{2}$, Stephen H Boutcher ${ }^{1}$, Yati N Boutcher, ${ }^{1, *}$ \\ ${ }^{1}$ School of Medical Sciences, Faculty of Medicine, University of New South Wales, Sydney, Australia \\ ${ }^{2}$ University of British Columbia, Canada
}

Copyright $\bigcirc 2018$ by authors, all rights reserved. Authors agree that this article remains permanently open access under the terms of the Creative Commons Attribution License 4.0 International License

\begin{abstract}
Overweight compared to normal weight individuals typically possess reduced limb blood flow at rest and during mental challenge. The effect of a single bout of aerobic exercise on cardiovascular reactivity of young overweight males, however, is undetermined. Thus, the purpose was to examine the cardiovascular reactivity response of overweight males to mental challenge before and after acute aerobic exercise. Fifteen normal weight (NW) males with body mass index (BMI) between 18 and $25 \mathrm{~kg} / \mathrm{m}^{2}$ and 15 overweight males (OW) with BMI $>25$ $\mathrm{kg} / \mathrm{m}^{2}$ aged $18-30$ years acted as participants. All males underwent a 5 -min Stroop task before and after one single 30 -min bout of cycle exercise at $65 \%$ of maximal oxygen uptake $\left(\dot{\mathrm{V}}_{2 \max }\right)$. Heart rate, blood pressure, arterial stiffness, and forearm blood flow (FBF) were assessed during Stroop task before and after acute exercise. Arterial stiffness of the OW was significantly higher than NW during Stroop before $(p=0.01)$ and after exercise $(p=$ $0.001)$. After exercise, the $\mathrm{OW}$ had significantly smaller increase in FBF throughout Stroop $(p=0.04)$ compared to NW. The smaller increase in FBF throughout the Stroop in the OW was also accompanied by higher Stroop errors compared to that of NW $(p=0.01)$. Stroop errors were positively correlated with BMI, waist circumference, waist/hip ratio, and body fat percentage, whereas post-exercise $\mathrm{FBF}$ was positively correlated with $\dot{\mathrm{V}}_{2 \max }(p$ $<0.05$ ). Being overweight was associated with a blunted FBF reactivity response and a greater number of errors during the Stroop task.
\end{abstract}

Keywords Acute Exercise, Overweight, Forearm Blood Flow, Arterial Stiffness, Blood Pressure

\section{Introduction}

Cardiovascular hyper-reactivity (a heightened cardiovascular response in relation to resting values) to mental challenge is thought to contribute to the development of cardiovascular disease [1-3]. Exaggerated cardiovascular reactivity to mental challenge typically involves elevated blood pressure (BP) and heart rate (HR).
Borderline hypertensives, who exhibited exaggerated BP response to a mental arithmetic task, were more likely to develop essential hypertension over a 5 -year period $[4,5]$.

Overweight and obese possess both a suppressed and heightened cardiovascular reactivity response to mental challenge. The enhanced skeletal muscle blood flow response to mental challenge typically found with normal weight adults is reduced in the obese [6,7] and cardiac output response is also blunted [8]. This reduced skeletal muscle blood flow during mental challenge causes an increase in systemic vascular resistance which results in an increase in BP [9]. Exaggerated arterial stiffness reactivity to mental arithmetic has also been found in obese males [10]. A number of studies have also shown that central adiposity, independent of total adiposity, is more strongly associated with the increased systemic vascular resistance and BP reactivity response to mental challenge [11]. Also, it has been shown that men and women with large waist circumference (WC) had exaggerated systolic and diastolic BP to mental challenge compared to low WC individuals, independent of BMI and total body fat [12].

The ability of an acute bout of aerobic exercise to normalize the cardiovascular reactivity response of normal weight adults has been examined by a number of studies [13]. Results show that acute exercise typically lowers BP reactivity [14] although reduced total peripheral vascular resistance to mental challenge has also been found $[15,16]$. The effect of acute exercise on cardiovascular reactivity response to mental challenge of overweight males following one single bout of aerobic exercise, however, has not been examined. Thus, it was hypothesised that a 30-min single bout of cycle exercise would normalize the cardiovascular reactivity of overweight males by significantly decreasing arterial stiffness and increasing forearm blood flow during mental challenge.

\section{Methods}

\section{Participants}

Fifteen normal weight $(\mathrm{NW})$ with body mass index 
(BMI) between 18 and $25 \mathrm{~kg} / \mathrm{m}^{2}$ and 15 overweight (OW) with BMI $>25 \mathrm{~kg} / \mathrm{m}^{2}$ aged 18 to 30 years participated in the study. Participants, who were mainly university students, were recruited predominantly by advertisement and word of mouth. Males who had chronic disease, required medication, or participated in aerobic exercise with the duration of $30 \mathrm{~min}$ for more than three times a week were excluded.

\section{Procedure}

In Session 1, anthropometric data including height, weight, waist and hip circumference, and maximal oxygen uptake $\left(\mathrm{V}_{2 \max }\right)$ were collected. Body fat percentage and weight were determined using a Tanita Body Composition Analyser (TBF-300). WC was measured using a tape measure at the level of the umbilicus whereas hip circumference was measured at the widest part of the gluteus maximus muscle. HR was measured after 5 min of rest in a seated position followed by measurement of BP using a mercury sphygmomanometer. All participants underwent a $\dot{\mathrm{V}} \mathrm{O}_{2 \max }$ test on an electronic bike (Monark E319, Sweden) and gases were collected and analysed by a Parvomedic metabolic cart (TrueOne model 2400, ParvoMedics Inc., Utah, UT, USA). Participants were instructed to cycle at a cadence of 60 to 80 revolutions per minute (rpm). The load was initially set to $30 \mathrm{~W}$ and after 3 min of warm-up, was increased by $1 \mathrm{~W}$ every $2 \mathrm{~s}$. The test was completed when participants reached volitional exhaustion and the respiratory exchange ratio exceeded 1.10. The load required to reach $65 \%$ of their $\dot{\mathrm{V}} \mathrm{O}_{2 \max }$ was then calculated.

In Session 2, at least 24 hours following Session 1, cardiovascular response at baseline and during the Stroop task, was assessed at pre and post exercise. Stroop is a colour-word conflict task which requires participants to name the colour of a word, instead of reading the word [17]. All males underwent a 5-min baseline cardiovascular measurement and the 5-min Stroop task before and after exercise. Mistakes and errors were also recorded during Stroop. Once baseline cardiovascular function was assessed, participants then performed one single 30-min bout of acute exercise.

Exercise was performed on a stationary bike (Monark Ergomedic 828E, Vansbro, Sweden), with participants performing a 5-min warm-up period before commencing exercise. Exercise involved cycling at a cadence of 60 to 80 rpm for $30 \mathrm{~min}$, with a load set at $65 \%$ of participant's $\dot{\mathrm{V}}_{2 \max }$. A 5-min cool-down period was also included. During exercise, HR was monitored continuously and recorded every 5 min using a Polar S8101 HR monitor (Polar, Electro, Kemple, Finland) to ensure that participants were exercised at the appropriate intensity. Following acute exercise, participants then resumed a seated upright position in order to perform the post exercise Stroop task. All cardiovascular variables at rest and during
Stroop then were assessed as at pre exercise.

\section{Measures}

\section{Arterial stiffness}

Arterial stiffness was assessed through augmentation index (AIx), which is a surrogate measure of arterial stiffness. AIx was obtained by placing an applanation tonometry sensor on a radial artery and was derived from the ratio of augmented pressure (AP) and pulse pressure (PP). Twenty consecutive waveforms were recorded to analyze AIx. Applanation tonometry (SphygmoCor 2000, AtCor Medical, Sydney, Australia) is a reliable, valid measure of arterial stiffness and has been compared favorably with Complior (Complior SP, Artech Medical, Pantin, France) and VaSera (VaSera VS-1000, Fukuda, Denshi, Tokyo, Japan) devices [18].

\section{Forearm blood flow}

Forearm blood flow (FBF) was assessed using strain gauge plethysmography with venous occlusion technique when participants were in an upright seated position. Mercury strain gauges that were 2 to $3 \mathrm{~cm}$ less than the circumference of the right forearm were attached $5 \mathrm{~cm}$ distal to the cubital fossa while cuffs were placed around the wrist and upper arm. The wrist cuff was inflated to suprasystolic pressure $1 \mathrm{~min}$ prior to measurement and maintained for the duration of the test in order to exclude circulation relating to the hand [19]. Baseline FBF was determined by inflating the cuff on the upper arm to 50 $\mathrm{mmHg}$ for $5 \mathrm{~s}$, every $15 \mathrm{~s}$, in order to occlude venous drainage from the forearm. The increase in the volume of the arm is proportional to the arterial inflow [19] and the strain gauge measures this by an increase in resistance as it is stretched. The increase in resistance was recorded using customized software (BP monitor, UNSW) and the gradient of the line reflected the flow rate.

\section{Blood pressure and heart rate}

Systolic and diastolic BP was assessed using a beat-by-beat BP recording of the radial pulse waveform (Jentow, Colin Electronics, Komaki, Japan), whereas HR was assessed by analysing the time interval between $\mathrm{R}$ spikes (sampling rate $1000 \cdot \mathrm{sec}^{-1}$ ) obtained from the ECG recording. Electrodes were attached to the participants' chest and connected to an ECG, allowing the ECG wave to be recorded using BP Monitor. Baseline HR was obtained from the average HR over 5 min duration. During Stroop, $\mathrm{HR}, \mathrm{BP}$ and FBF was recorded and averaged every minute for $5 \mathrm{~min}$.

\section{Statistical analyses}

Statistical analysis was performed using the statistical package for social sciences (SPSS) V20 software. Differences between groups for participant characteristics 
and baseline cardiovascular variables were analysed using independent $t$-tests. To adjust for differences in baseline values between the two groups the analysis was performed on the change scores (baseline post-exercise minus pre-exercise baseline). A two-way mixed between-within analysis of variance (ANOVA) 2 (groups) x 2 (conditions; pre and post) x 5 measurement points (every minute of 5 minutes of Stroop task) was used to compare Stroop performance of the NW and OW groups at pre and post exercise. Greenhouse-Geiser adjustment was used when the Sphericity value was not assumed. Pearson product-moment correlation was also used to assess the relationship between variables. The analysis was deemed significant when the probability value was less than 0.05 .

\section{Ethical aspects}

The study protocol was approved by a university Ethics Committee and conformed to the declaration of Helsinki. Informed written consent was obtained before testing.

\section{Results}

\section{Participant characteristics}

There were no significant differences in age, height, SBP, $\dot{\mathrm{V}} \mathrm{O}_{2 \max }$, and resting HR between groups. Overweight males possessed significantly greater weight, BMI, diastolic BP,
WC, hip circumference $(\mathrm{HC})$, waist-to-hip ratio $(\mathrm{W} / \mathrm{H})$, and body fat percentage (Table 1).

\section{HR and BP at pre, during, and post-acute exercise}

There was no significant difference in the average HR during exercise between NW $(164 \pm 2.8)$ and OW $(167 \pm$ $1.8)$ groups, $p>0.05$. There were no significant differences between systolic and diastolic BP measured at baseline compared to the measurements made after exercise. Also, systolic and diastolic BP response throughout exercise was similar for both groups.

\section{Cardiovascular variables during the Stroop task before and after exercise}

There was no significant difference in baseline augmentation index change (post-exercise AIx minus baseline AIx) between groups (Figure 1). However, during Stroop, there was a significant time main effect, $F(4,104)=3.29, p=0.014, \eta^{2}=0.11$ and a between group effect $F(1,26)=7.66, p=0.01, \eta^{2}=0.23$ in augmentation index at pre exercise (Figure 1). Also, during the Stroop there was a significant time main effect, $F(2.34,49.2)=5.39$, $p=0.005, \eta^{2}=0.20$ and a between group effect $F(1,21)=21.8$, $p=0.001, \eta^{2}=0.51$ in augmentation index at post-exercise (Figure 1).

Table 1. Physical characteristics and baseline cardiovascular variables of normal weight (NW) and overweight (OW) males. Data are means and standard errors of the mean in brackets; $(*)$ indicates significant differences between groups.

\begin{tabular}{lccc}
\hline Variable & NW $(\mathrm{n}=15)$ & OW $(\mathrm{n}=15)$ & $\mathrm{p}$ value \\
\hline Age (years) & $20(0.2)$ & $21(0.6)$ & $\mathrm{p}=0.06$ \\
Height $(\mathrm{cm})$ & $177(1.6)$ & $174(1.9)$ & $\mathrm{p}=0.28$ \\
Weight $(\mathrm{kg})$ & $69(1.9)$ & $85(4.6)^{*}$ & $\mathrm{p}=0.004$ \\
BMI $\left(\mathrm{kg} / \mathrm{m}^{2}\right)$ & $22(0.4)$ & $28(0.9)^{*}$ & $\mathrm{p}<0.001$ \\
Body fat percentage $(\%)$ & $12(0.7)$ & $22(1.8)^{*}$ & $\mathrm{p}<0.001$ \\
Resting heart rate $(\mathrm{bpm})$ & $67(2.3)$ & $72(2.1)$ & $\mathrm{p}=0.17$ \\
SBP $(\mathrm{mmHg})$ & $118(1.8)$ & $124(2.4)$ & $\mathrm{p}=0.06$ \\
DBP $(\mathrm{mmHg})$ & $72(1.5)$ & $79(2.1)^{*}$ & $\mathrm{p}=0.01$ \\
WC $(\mathrm{cm})$ & $75(1.0)$ & $92(2.9)^{*}$ & $\mathrm{p}<0.001$ \\
$\mathrm{HC}(\mathrm{cm})$ & $91(1.2)$ & $102(2.4)^{*}$ & $\mathrm{p}=0.001$ \\
$\mathrm{~W} / \mathrm{H}$ & $0.8(0.01)$ & $0.9(0.02)^{*}$ & $\mathrm{p}<0.001$ \\
$\mathrm{VO}_{2} \mathrm{max}(\mathrm{ml} / \mathrm{kg} / \mathrm{min})$ & $42(1.9)$ & $38(2.1)$ & $\mathrm{p}=0.17$
\end{tabular}

BMI: body mass index; SBP; systolic blood pressure; DBP: diastolic blood pressure; WC: waist circumference; HC: hip circumference; W/H: waist-hip ratio. 


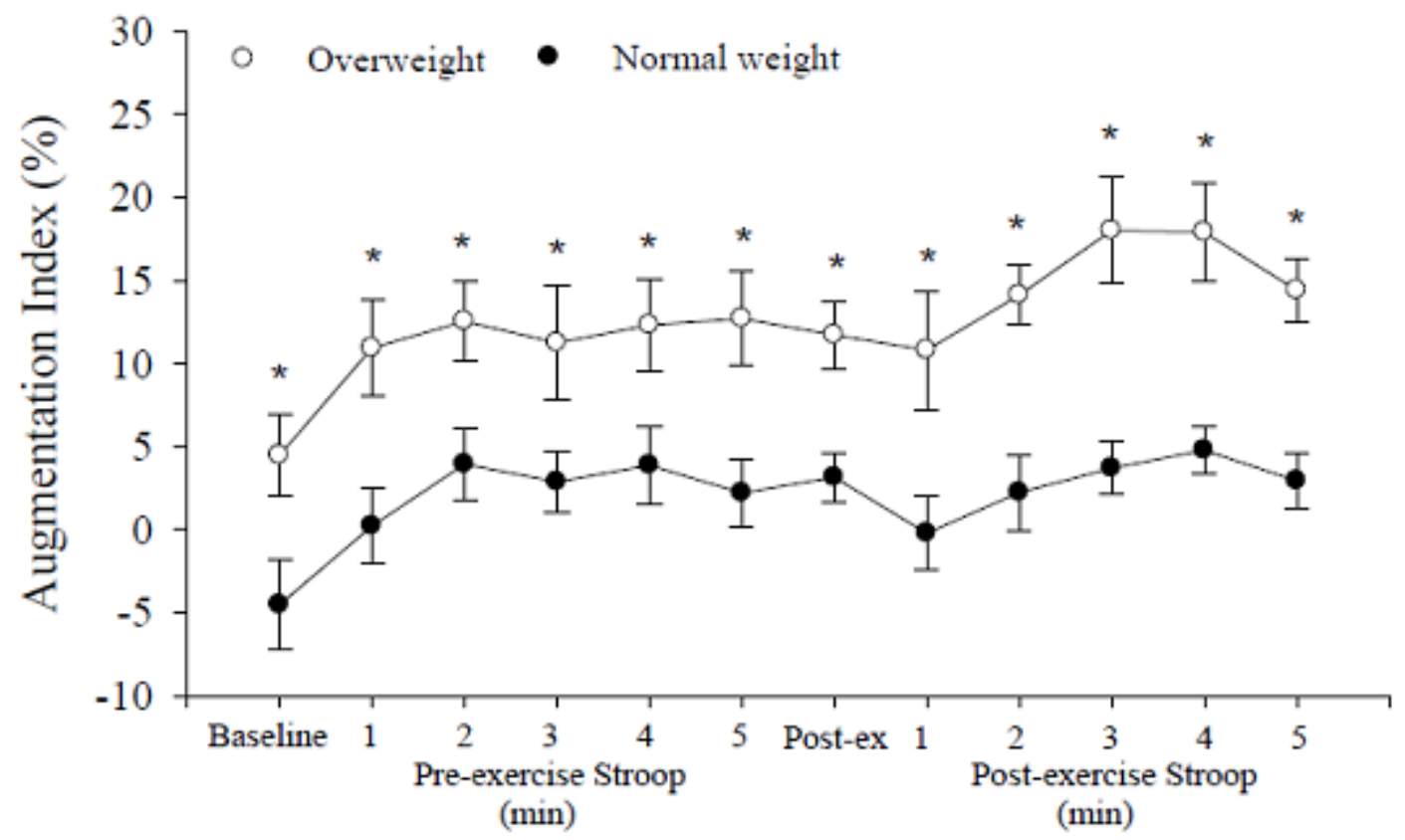

Figure 1. AIx responses at baseline and during Stroop task at pre and post exercise for both groups. *Significant differences between groups, at $p<$ 0.05 .

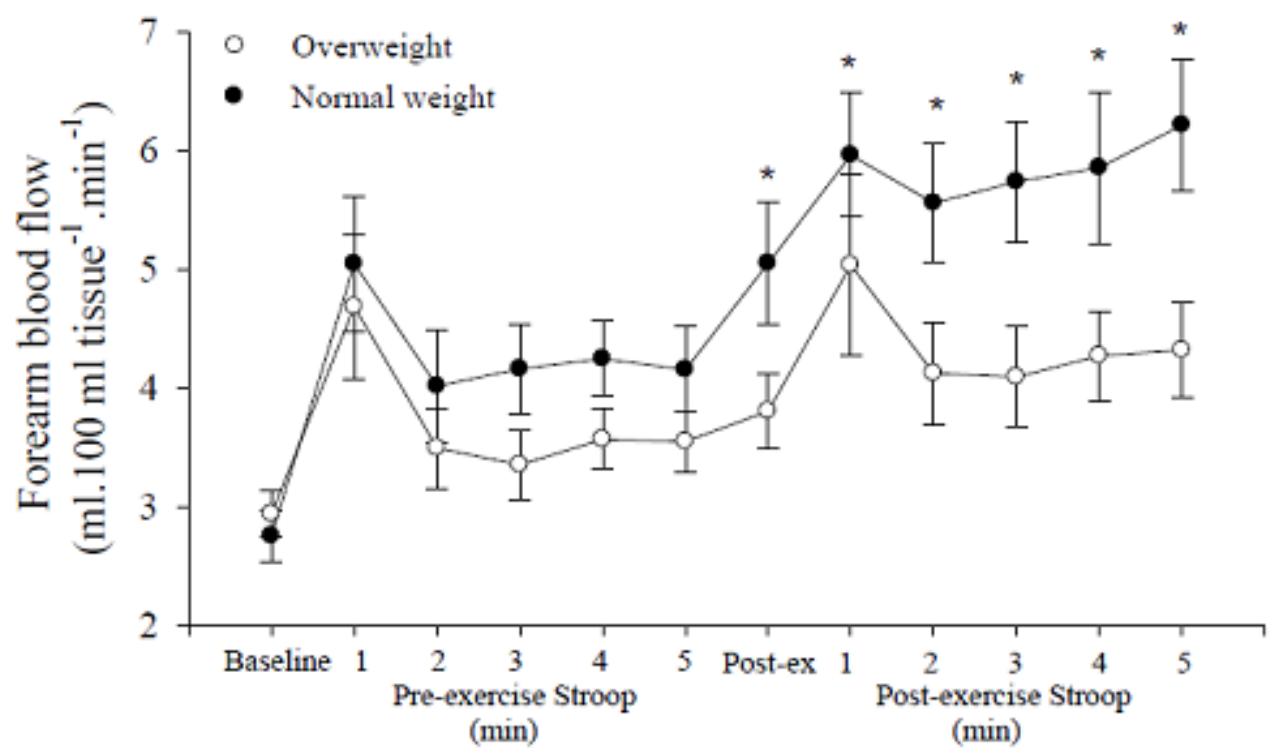

Figure 2. Forearm blood flow responses at baseline and during Stroop task at pre and post exercise for both groups. *Significant differences between groups at post-exercise and during Stroop task at post-exercise, at $p<0.05$

There was no significant correlation between pre-exercise arterial stiffness and WC, however, post-exercise arterial stiffness exercise was significantly correlated, $p<0.05$, with waist circumference $(r=0.46)$. There was a significant difference in baseline FBF change (post-exercise FBF minus baseline FBF) between groups, $t(28)=2.35, \quad p=0.026$. The NW post-exercise FBF increased by $2.41 \pm 0.48 \mathrm{ml} \cdot 100 \mathrm{ml}$ tissue ${ }^{-1} \cdot \mathrm{min}^{-1}$ compared to the OW who increased by $1.06 \pm 0.32 \mathrm{ml} \cdot 100 \mathrm{ml}$ tissue $^{-1} \cdot \mathrm{min}^{-1}$ (Figure 2).
There was a significant time main effect, $F(1.71,37.9)=8.96, p=0.001, \eta^{2}=0.29$ with no significant between group effect in FBF at pre-exercise Stroop. At post-exercise, however, there was a significant between group effect in FBF throughout the Stroop, $F(1,21)=4.39, p$ $=0.04, \eta^{2}=0.17$ (Figure 2). There were no significant differences in HR, systolic, diastolic, and mean arterial BP at baseline and during the Stroop task at pre- and postacute exercise (Table 2). 
Table 2. Heart rate and blood pressure of normal weight (NW) and overweight (OW) participants at baseline/rest and during Stroop task. Data are means and standard errors of the mean in brackets.

\begin{tabular}{|c|c|c|c|c|c|c|c|c|c|c|c|c|c|}
\hline \multirow{2}{*}{ Variables } & \multirow{2}{*}{ Groups } & \multicolumn{6}{|c|}{ Pre exercise } & \multicolumn{6}{|c|}{ Post exercise } \\
\hline & & Baseline & $\mathrm{S} 1$ & $\mathrm{~S} 2$ & $\mathrm{~S} 3$ & $\mathrm{~S} 4$ & S5 & Resting & $\mathrm{S} 1$ & $\mathrm{~S} 2$ & S3 & $\mathrm{S} 4$ & S5 \\
\hline \multirow{2}{*}{ HR } & NW & $\begin{array}{c}66 \\
(2.5)\end{array}$ & $\begin{array}{c}78 \\
(2.8)\end{array}$ & $\begin{array}{c}73 \\
(2.7)\end{array}$ & $\begin{array}{c}73 \\
(2.6)\end{array}$ & $\begin{array}{c}74 \\
(2.5)\end{array}$ & $\begin{array}{c}75 \\
(2.7)\end{array}$ & $96(3.0)$ & $\begin{array}{c}94 \\
(3.5)\end{array}$ & $\begin{array}{c}92 \\
(3.3)\end{array}$ & $\begin{array}{c}92 \\
(3.3)\end{array}$ & $\begin{array}{c}91 \\
(3.2)\end{array}$ & $\begin{array}{c}92 \\
(3.4) \\
\end{array}$ \\
\hline & OW & $\begin{array}{c}66 \\
(1.3)\end{array}$ & $\begin{array}{c}74 \\
(2.4)\end{array}$ & $\begin{array}{c}71 \\
(1.7)\end{array}$ & $\begin{array}{c}71 \\
(1.5)\end{array}$ & $\begin{array}{c}71 \\
(2.0)\end{array}$ & $\begin{array}{c}71 \\
(1.7)\end{array}$ & $95(1.8)$ & $\begin{array}{c}94 \\
(3.3)\end{array}$ & $\begin{array}{c}91 \\
(2.6)\end{array}$ & $\begin{array}{c}91 \\
(2.4)\end{array}$ & $\begin{array}{c}91 \\
(2.5)\end{array}$ & $\begin{array}{c}92 \\
(2.7) \\
\end{array}$ \\
\hline \multirow{2}{*}{ SBP } & NW & $116(1.4)$ & $\begin{array}{c}128 \\
(3.4)\end{array}$ & $\begin{array}{c}129 \\
(3.8)\end{array}$ & $\begin{array}{c}129 \\
(3.9)\end{array}$ & $\begin{array}{c}128 \\
(3.6)\end{array}$ & $\begin{array}{c}127 \\
(3.3)\end{array}$ & $\begin{array}{c}114 \\
(3.2)\end{array}$ & $\begin{array}{c}130 \\
(4.7)\end{array}$ & $\begin{array}{c}129 \\
(5.5)\end{array}$ & $\begin{array}{c}133 \\
(5.6)\end{array}$ & $\begin{array}{c}128 \\
(5.4)\end{array}$ & $\begin{array}{c}131 \\
5.3 \\
\end{array}$ \\
\hline & OW & $116(3.3)$ & $\begin{array}{c}133 \\
(7.0)\end{array}$ & $\begin{array}{c}133 \\
(8.1)\end{array}$ & $\begin{array}{c}133 \\
(9.1)\end{array}$ & $\begin{array}{c}132 \\
(9.7)\end{array}$ & $\begin{array}{c}132 \\
(9.8)\end{array}$ & $\begin{array}{c}116 \\
(3.3)\end{array}$ & $\begin{array}{l}129 \\
(5.1\end{array}$ & $\begin{array}{c}131 \\
(5.6)\end{array}$ & $\begin{array}{c}126 \\
(6.2)\end{array}$ & $\begin{array}{c}123 \\
(6.2)\end{array}$ & $\begin{array}{c}134 \\
(8.5)\end{array}$ \\
\hline \multirow{2}{*}{ DBP } & NW & $\begin{array}{c}68 \\
(2.2)\end{array}$ & $\begin{array}{c}60 \\
(2.2)\end{array}$ & $\begin{array}{c}62 \\
(2.1)\end{array}$ & $\begin{array}{c}63 \\
(2.4)\end{array}$ & $\begin{array}{c}63 \\
(2.6)\end{array}$ & $\begin{array}{c}63 \\
(2.7)\end{array}$ & $\begin{array}{c}58 \\
(2.3)\end{array}$ & $\begin{array}{c}62 \\
(2.8)\end{array}$ & $\begin{array}{c}66 \\
(2.6)\end{array}$ & $\begin{array}{c}67 \\
(2.3)\end{array}$ & $\begin{array}{c}65 \\
(2.2)\end{array}$ & $\begin{array}{c}65 \\
(2.1) \\
\end{array}$ \\
\hline & OW & $\begin{array}{c}64 \\
(4.2)\end{array}$ & $\begin{array}{c}68 \\
(4.6)\end{array}$ & $\begin{array}{c}69 \\
(5.7)\end{array}$ & $\begin{array}{c}69 \\
(7.4)\end{array}$ & $\begin{array}{c}62 \\
(4.9)\end{array}$ & $\begin{array}{c}71 \\
(8.5)\end{array}$ & $\begin{array}{c}56 \\
(2.2)\end{array}$ & $\begin{array}{c}68 \\
(3.8)\end{array}$ & $\begin{array}{c}70 \\
(4.2)\end{array}$ & $\begin{array}{c}67 \\
(4.5)\end{array}$ & $\begin{array}{c}65 \\
(3.7)\end{array}$ & $\begin{array}{c}69 \\
(6.1) \\
\end{array}$ \\
\hline \multirow{2}{*}{ MAP } & NW & $\begin{array}{c}84 \\
(1.8)\end{array}$ & $\begin{array}{c}83 \\
(2.2)\end{array}$ & $\begin{array}{c}85 \\
(2.4)\end{array}$ & $\begin{array}{c}85 \\
(2.5)\end{array}$ & $\begin{array}{c}85 \\
(2.4)\end{array}$ & $\begin{array}{c}84 \\
(2.4)\end{array}$ & $77(2.4)$ & $\begin{array}{c}84 \\
(3.1)\end{array}$ & $\begin{array}{c}87 \\
(3.4)\end{array}$ & $\begin{array}{c}89 \\
(3.2)\end{array}$ & $\begin{array}{c}86 \\
(3.1)\end{array}$ & $\begin{array}{c}87 \\
(2.9)\end{array}$ \\
\hline & OW & $\begin{array}{c}81 \\
(3.7)\end{array}$ & $\begin{array}{c}89 \\
(4.9)\end{array}$ & $\begin{array}{c}92 \\
(6.2)\end{array}$ & $\begin{array}{c}90 \\
(7.8)\end{array}$ & $\begin{array}{c}85 \\
(5.4)\end{array}$ & $\begin{array}{c}92 \\
(8.8)\end{array}$ & $76(2.4)$ & $\begin{array}{c}88 \\
(3.9)\end{array}$ & $\begin{array}{c}90 \\
(4.5)\end{array}$ & $\begin{array}{c}87 \\
(4.8)\end{array}$ & $\begin{array}{c}84 \\
(4.3)\end{array}$ & $\begin{array}{c}91 \\
(6.8)\end{array}$ \\
\hline
\end{tabular}

\section{Stroop task errors}

There was a significant difference in Stroop errors change (post-Stroop errors minus pre-Stroop errors) between groups, $t(28)=2.78, p=0.010$ (Figure 3). Although both groups had reduced their Stroop mistakes at post-exercise, the OW $(20 \pm 2.83$ errors $)$ still made significantly more mistakes compared to the NW ( $8.27 \pm 3.13$ errors). The OW made on average 35 more mistakes at pre- and 23 more mistakes at post-exercise compared to that of the NW (Figure 3).

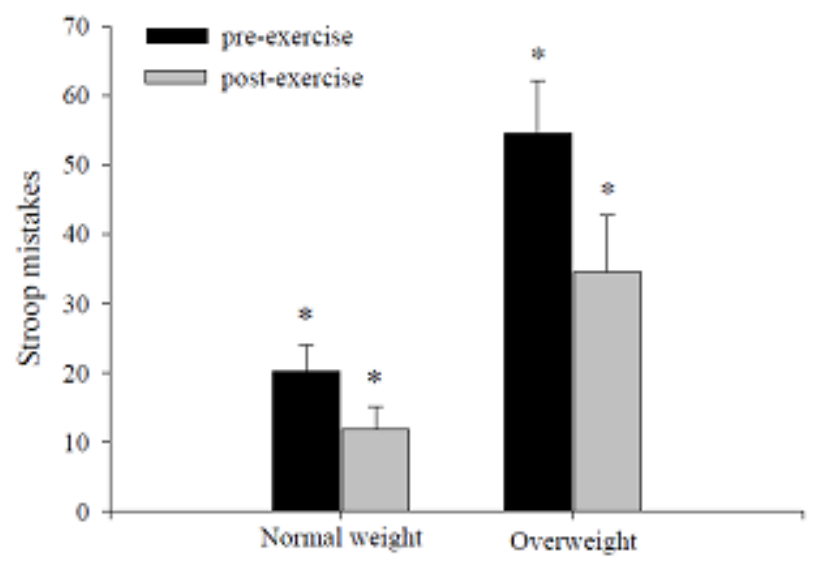

Figure 3. Stroop mistakes at pre and post exercise for both groups. *Significant differences between groups at pre and post exercise, at $p<0.05$

At pre-exercise, Stroop errors were significantly correlated, $p<0.05$, with BMI $(r=0.51)$, WC $(r=0.45)$, waist/hip ratio $(r=0.36)$, and body fat percentage $(r=0.49)$. Significant correlations for Stroop errors at post-exercise also existed for BMI $(r=0.52)$, WC $(r=0.45)$, and body fat percentage $(r=0.49), p<0.05$.

\section{Discussion}

The major findings were that the overweight possessed greater arterial stiffness at rest, throughout mental challenge, and before and after acute exercise compared to the normal weight. The overweight had lower FBF at rest and during Stroop after exercise. Also, the overweight compared to normal weight males made more mistakes during the Stroop task before and after exercise.

The elevated arterial stiffness at baseline supports prior research that has shown that the overweight and obese have greater resting arterial stiffness. Chronic elevated resting arterial stiffness is likely to have health implications as arterial stiffness is an independent predictor of myocardial infarction and stroke [20,21]. The higher arterial stiffness of the overweight males throughout the Stroop task, before and after exercise, supports prior research that has shown higher arterial stiffness levels during mental challenge in young obese males [10]. The arterial stiffness increase during Stroop of the overweight males was similar to that of the normal weight males. As it has been shown that resting arterial stiffness increases with both obesity and age [22] it is likely that as the overweight males get older their absolute levels of arterial resistance during mental challenge will be greater and outside the normal range. Thus, the health implications of elevated absolute levels of arterial stiffness during mental challenge of overweight individuals should be further examined.

Excess body fat, and especially visceral fat, may contribute to the high arterial stiffness found in the overweight as a modest diet-induced weight gain was found to increase arterial stiffness in healthy adult men and weight gain was highly correlated with visceral fat accumulation [23]. A number of cross-sectional studies have also shown that WC and arterial stiffness $[22,24]$ and WC and abdominal fat [25] are strongly correlated. Thus, although visceral fat was not assessed in the present study, it is feasible that because arterial stiffness was significantly 
correlated with WC, visceral fat may have contributed to the greater arterial stiffness of the overweight.

The mechanism(s) underlying the relationship between visceral fat and arterial stiffness are unclear. It has been suggested that excessive weight gain is accompanied by the proinflammatory state and increased oxidative stress that alter vascular structure and function by disrupting the balance of key extracellular matrix proteins (i.e., elastin and collagen) and vasoconstrictive and vasodilatory substances (e.g., nitric oxide, prostacyclins, endothelin-1, and angiotensin II) [26]. Vasoconstrictive and vasodilatory substances also promote vascular smooth muscle cell hypertrophy that can lead to arterial stiffening [26].

There was no difference in resting FBF before or after exercise between groups. Overweight individuals, however, showed smaller increase in FBF throughout the Stroop task before and after exercise compared to the normal weight. Inability to dilate the smooth muscle of the arterioles in the overweight in response to the Stroop task suggests that endothelial dysfunction had already occurred in this group of young overweight males. Less responsiveness of the $\beta-2$ adrenoreceptors to Stroop-induced epinephrine increase [27] in the overweight may also have contributed to the inability of the overweight arterioles to dilate, resulting in reduced $\mathrm{FBF}$.

A reduction in sympathetic outflow to the forearm skeletal muscle has been shown to be one of the contributing mechanisms to the elevated skeletal muscle blood flow typically seen during Stroop performance [28]. It has been shown that the Stroop task excites cardiopulmonary baroreceptors which then attenuate sympathetic outflow to the forearm vasculature causing muscle vasodilation [29]. Other Stroop-induced vasodilatory mechanisms such as Stroop-induced elevations in shear stress causing release of vasodilatory substances such as nitric oxide $[28,30]$ may also have contributed to the rise in skeletal muscle blood flow and vascular conductance.

The inability to vasodilate arterioles, resulting in low FBF, suggests that endothelial dysfunction and reduced responsiveness of $\beta-2$ adrenoreceptors, as well as heightened sympathetic outflow, may have already occurred in these young overweight males. It has been suggested that the blunted vascular response of the obese to mental challenge reflects the presence of endothelial dysfunction [31]. It is also possible, however, that impaired vasodilation may have been influenced by visceral fat as modest visceral fat gain has been shown to cause endothelial dysfunction in young healthy adults [32]. As previously mentioned although visceral fat was not assessed in the current study there is a strong relationship between WC and visceral fat [25]. In the present study the overweight possessed a WC of $92 \mathrm{~cm}$ which was $23 \%$ greater than that of the normal weight. Possible mechanisms connecting visceral fat to endothelial dysfunction include elevated proinflammatory cytokine and adipokine levels $[33,34]$.

That the overweight made significantly more mistakes during the Stroop task at pre and post exercise compared to the normal weight was surprising. It seems that the overweight condition may have impaired the ability to perform the Stroop task. Although Stroop mistakes were reduced after exercise in the overweight, the number of mistakes was higher in the overweight than that of the normal weight before and after exercise. It is not clear why the overweight's Stroop task performance was not similar to that of the normal weight, however, impaired cognitive function accompanying the overweight condition may play a role in Stroop performance as it has been shown that decreased cognitive performance was linked to overweight in a paediatric population [35]. Epidemiological studies have also shown that overweight adults demonstrate decrements in memory, abstract reasoning, and attention [36]. It has also been suggested that impaired cognitive function could be due to impaired insulin receptor signalling accompanied by delayed or absent myelination or demyelination of neurons [37,38]. Whatever the mechanism the association found between Stroop mistakes and body fat suggests that being overweight has a negative effect on cognitive function.

As overweight males were aged in their early twenties it is unclear if these results are similar for older males who have been obese for a much longer period. Also the $\mathrm{WC}$ of the overweight men was $92 \mathrm{~cm}$ indicating moderate levels of abdominal obesity. Thus, the mental challenge response of individuals possessing much greater levels of abdominal obesity also needs to be examined.

Overall, these results suggest that the Stroop task performed before and after a short bout of aerobic exercise caused significant cardiovascular and FBF reactivity in both groups with the overweight showing greater arterial stiffness but less FBF responsiveness. The overweight compared to normal weight males also made significantly more mistakes during Stroop task.

\section{REFERENCES}

[1] Krantz DS, Manuck SB. Acute psychophysiologic reactivity and risk of cardiovascular disease: a review and methodological critique. Psychol Bulletin 1984;96: 435-464.

[2] Matthews KA, Salomon K, Brady SS, Allen MT. Cardiovascular reactivity to stress predicts future blood pressure in adolescence. Psychosom Med 2003;65:410-415.

[3] Treiber FA, Kamarck T, Schneiderman N, Sheffield D, Kapuku G, Taylor T. Cardiovascular reactivity and development of preclinical and clinical disease states. Psychosom Med 2003;65: 46-62. 
[4] Borghi C, Costa F, Boschi S, Mussi A, Ambrosioni E. Predictors of stable hypertension in young borderline subjects: a five-year follow-up study. J Cardiovasc Pharmacol 1986;8:S138-141.

[5] Falkner B, Kushner H, Onesti G, Angelakos ET. Cardiovascular characteristics in adolescents who develop essential hypertension. Hypertens 1981;3:521-527.

[6] Agapitov AV, Correia ML, Sinkey CA, Dopp JM, Haynes WG. Impaired skeletal muscle and skin microcirculatory function in human obesity. J Hypertens 2002;20: 1401-1405.

[7] Kuniyoshi FHS. Abnormal neurovascular control during sympathoexcitation in obesity. Obes Res 2003;11:1411-1419.

[8] Jaju D, Al Abri M, Hassan MO, Alvarenga JL, Comuzzie A, et al. Hemodynamic and autonomic reactivity to mental and physical stress in lean, overweight and obese subjects. J Obes Overweig 2016;2(1): 105. doi: $10.15744 / 2455-7633.2 .105$

[9] Seematter G. Effects of mental stress on insulin-mediated glucose metabolism and energy expenditure in lean and obese women. Am J Physiol 2000;279:E799-E805.

[10] Tabara Y, Kohara K, Nakagawa S et al. Effects of obesity and smoking on mental stress-induced blood pressure and augmentation index responses in normotensive young males: The J-SHIPP study. Hypertens Res 2008;31:1219-1224.

[11] Huang C-J, Webb HE, Zourdos MC, Acevedo EO. Cardiovascular reactivity, stress, and physical activity. Front $\quad$ Physiol 2013;4: 314. doi:10.3389/fphys.2013.00314.

[12] Goldbacher EM, Matthews K. Central adiposity as associated with cardiovascular reactivity to stress in adolescents. Health Psychol 2005;24(4):375-384.

[13] Hamer M, Taylor A, Steptoe A. The effect of acute aerobic exercise on stress related blood pressure responses: A systematic review and meta- analysis. Bio Psychol 2006a;71:183-190.

[14] Brownley KA, Hinderlitter AL, West SG, Girdler SS, Sherwood KA, Light KC. Sympathoadrenergic mechanisms in reduced hemodynamic stress responses after exercise. Med Sci Sports Exerc 2003;35:978-986.

[15] Hamer M, Jones J, Boutcher SH. Acute exercise reduces vascular reactivity to mental challenge in offspring of hypertensive families. J Hypertens 2006b;24:315-320.

[16] West SG, Brownley KA, Light KC. Post-exercise vasodilatation reduces diastolic blood pressure responses to stress. Ann Behavior Med 1998;20:77-83.

[17] Stroop JP. Studies in interference in serial verbal reactions. J Experim Psychol 1935; 18:643-662.

[18] Huck CJ, Bronas UG, Williamson EB, Draheim CC, Duprez DA, Dengel DR. Noninvasive measurements of arterial stiffness: Repeatability and interrelationships with endothelial function and arterial morphology measures. Vasc Health Risk Manage 2007; 3:343-349.

[19] Boutcher YN, Hopp J, Boutcher SH. Acute effect of a single bout of aerobic exercise on vascular and baroreflex function of young males with a family history of hypertension. J Hum Hypertens 2011; 25: 311-319.

[20] Laurent S, Cockcroft J, Van Bortel et al. Expert consensus document on arterial stiffness: methodological issues and clinical applications. Europ Heart J 2006;27:2588-2605.

[21] Vlachopoulos C, Aznaouridis K, Stefanadis C. Predicition of cardiovascular events and all-cause mortality with arterial stiffness: a systematic review and meta-analysis. J Am Coll Cardiol 2010; 55:1318-1327.

[22] Sutton-Tyrrell K, Newman A, Simonsick EM, Havlik R, Pahor M, Lakatta E, Spurgeon, H, Vaitkevicius P. Aortic stiffness is associated with visceral adiposity in older adults enrolled in the study of health, aging, and body composition. Hypertens 2001; 38: 429-433.

[23] Orr JS, Gentile CL, Davy BM, Davy KP. Large artery stiffening with weight gain in humans: role of visceral fat accumulation. Hypertens 2008; 51:1519-1524.

[24] Wildman RP, Mackey RH, Bostom A, Thompson T, Sutton-Tyrrell K. Measures of obesity are associated with vascular stiffness in young and older adults. Hypertens 2003;42:468-473.

[25] Guo Z, Hensrud DD, Johnson CM, Jensen MD. Regional postprandial fatty acid metabolism in different obesity phenotypes. Diabetes 1999; 8:1586-1592.

[26] Seals DR, Gates PE. Stiffening our resolve against adult weight gain. Hypertens 2005; 45:175-177.

[27] Boutcher YN, Boutcher SH. Cardiovascular response to Stroop: effect of verbal response and task difficulty. Biol Psychol 2006; 73(3):235-41.

[28] Freyschuss U, Hjemdahl P, Juhlin-Dannfelt A, Linde B. Cardiovascular and sympatho adrenal responses to mental stress; influence of B-blockade. Am J Physiol 1998;255:H1443-H1451.

[29] Hamer M, Boutcher YN, Boutcher SH. The role of cardiopulmonary baroreceptors during the forearm vasodilatation response to mental stress in humans. Psychophysiol 2003; 40:249-253.

[30] Khan SG, Melikian N, Shabeeh H, Cabaco AR, Martin K, $\mathrm{Khan} \mathrm{F}$. et al. The human coronary vasodilatory response to acute mental stress is mediated by neuronal nitric oxide synthase. Am J Physiol Heart Circ Physiol 2017;313: H578H583.

[31] Seematter G. Stress and metabolism. Met Syndr Rel Dis $2005 ; 3: 8-13$.

[32] Despre JP. Excess visceral adipose tissue/ectopic fat. J Am Coll Cardiol 2011;57(19):1887-1889.

[33] Nakamura K, Fuster JJ, Walsh K. Adipokines: A link between obesity and cardiovascular disease. J Cardiol 2014;63:250-259.

[34] Votruba SB, Jensen MD. Regional fat deposition as a factor in FFA metabolism. Ann Rev Nutrit 2007; 27:149-163.

[35] Cosgrove RG, Arroyo C, Warren JC, Zhang J. Impaired cognitive functioning in overweight children and adolescents. Obesity 2009; 20:48-51. 
[36] Trakas K, Oh PI, Singh S, Risebrough N, Shear NH. The health status of obese individuals in Canada. Inter J Obes Rel Met Dis 2001;25(5):662-668.

[37] Craft S, Watson GS. Insulin and neurodegenerative disease: shared and specific mechanisms. Lancet Neurol 2004; 3(3):169-178.

[38] Farr SA, Banks WA, Morley JE. Effects of leptin on memory processing. Peptides 2006;27(6):1420-1425. 